\title{
INVESTIGATION OF THE EFFICIENCY OF LABOUR SAFETY MEANS BY STATISTICAL GAMES
}

\author{
Petras Čyras ${ }^{1}$, Sigutè Vakriniené ${ }^{2}$ \\ ${ }^{\prime}$ Dept of Labour Safety and Fire Protection, Vilnius Gediminas Technical University. \\ Sauletekio al. 11, LT 2040 Vilnius, Lithuania. E-mail: Petras. Cyras@st.vtu.lt \\ 2 Dept of Mathematical Sciences, Vilnius Gediminas Technical University, \\ Sauletekio al. 11, LT 2040 Vilnius, Lithuania
}

Received 12 March 2001: accepted 15 May 2002

\begin{abstract}
Statistical data regarding causes and number of accidents in enterprises and organisations allow to foresee the average number of traumas for a definite period when no additional means for trauma prevention have been provided. The trauma prevention means differ because they require different financing and decreasing the number of traumas. The suggested mathematical methods give the possibility to appraise the means of trauma prevention according to the definite sum invested.

Some accidents are related to individual miss-steps/mistakes at work. Trying to find out the ways for optimal trauma prevention we can take the latter causes as statistical game of "nature" state and certain possible situations of existing in determination. They are impossible to be changed, though some preventive means applied by employees may decrease the trauma cases caused by individual safe control violation.

As soon as the optimal strategy of the aforementioned matrix game is found, the most important preventive means could be determined. They could guarantee the real decrease of the trauma cases in spite of any violations by employees. A certain modification of the straightforward programme making task allows us to get an optimal allocation of means necessary for trauma prevention, thus evaluating the effectiveness of preventive measures when the optimal financing is found as the means are increasing.
\end{abstract}

Keywords: trauma, traumatise, mixed strategies, game value.

\section{Introduction}

Nature gives the man the possibility to enjoy life for quite a long time and have benefit from using work tools and material assets created by him. Upon starting our working day we have to check with our biological clock regulating the right and proper working condition of the human being.

According to the world-wide Labour Safety and Sanitary Encyclopaedia, every year some 100000 people die as a result of industrial/occupational injuries/traumas. It has been established that work-time losses related with accidents exceed those related to conflicts at work by $4-5$ times.

It has been noticed while analysing injury causes for several years that from the psychophysical point of view at the beginning of the second work-hour employees find themselves unprepared to perform complex tasks, which results in traumas. Work organisational difficulties also matter in this regard. The seventh hour witnesses more injuries - employees are tired and hurry up to finish the work at the end of the shift-time.
The largest number of accidents on building sites takes place as a result of non-compliance with the regulations, ie improper organisation of work, unsafe or improper workplace and work environment, insufficient training, work without use of safety facilities and special clothes [1]. The main causes of injuries do not vary much from year to year. The most frequent ones are work discipline violations and organisational faults that do not require heavy expenses and can be eliminated by preventive means.

Due to economic and financial difficulties, many Lithuanian business entities become very sluggish in introducing safe work facilities, which (owing to the suffered traumas) result in much bigger financial losses related to payment of pecuniary fines and compensation for the damage done to health of the injured employees. Concrete preventive means intended for reducing the number of accidents usually become the object of planning and priority. They are also included in the plans of activities.

The task of optimization of preventive measures against natural calamities can be modelled as a matrix game [2] (elements of the matrix - losses related to the implementation of such measures and natural calamities). 
Matrix games were used for implementing organizational-technological solutions of the large-block / largeslab dwelling houses [3].

The article [4] covers the application of the theory of games with the aim of solving potential risks and complex issues of the automated fire safety systems of industrial enterprises. There are also game methods provided for managing the fire extinguishing resources and optimizing fire safety facilities.

The adoption of the optimum solution according to Bajes' criterion (when conditions are defined by weight coefficients) is covered by Article [5], [6], which is applied for solving issues related to changing, purchasing and updating of the facilities.

The Article [7], [8], upon assessing the risk, lays out the modelling of a simplified (cheapened) problem of the warehouse/storehouse inventory by applying the mini-max risk criterion. In our case, in the conditions of complete indetermination/vagueness, the mini-max criterion is used for mixed strategies.

The objective of this article is to offer mathematical methods for investigating comparative efficiency of the preventive means for industrial injuries and to determine the principle of optimal allocation of funds assigned for trauma prevention.

For modelling the problem, the matrix game is used with the elements of average number of traumas resulted from the absence of safety tools and related to cases of negligence, thus ignoring the monetary assessment of fatal and grave traumas, which often seems to be impossible. Upon modifying the problem of rectilinear programming, encompassing the aforementioned matrix game, we get the optimum distribution of funds allotted to trauma prevention.

\section{Matrix game simulation/modelling}

When analysing variation of the number of traumas according to causes of accidents [1] we can see that part of causes may be eliminated (at least partially), thus reducing the number of the traumatised (number of traumas suffered as a result of these causes). Naturally, in this case the employers would have to ensure an optimal allocation of funds intended for improvement of trauma preventive means.

Some accidents are related to individual missteps/ mistakes at work: negligence, disregard of labour safety means, drunkenness, etc.

Trying to find out the ways for optimal investing of funds allocated for trauma prevention we can consider the latter causes as "nature" states of statistical matrix game, ie certain possible situation of the currently existing in determination that cannot be changed. However, some preventive means applied by employers may decrease the traumas caused through violation of individual labour safety regulations.

Statistical data regarding the number of accidents in enterprises and organisations allow us to assert that the elimination of such causes as improper work organisation, insufficient supervision, non-compliance of workplaces, work environment and work territories with safety regulation requirements, negligence in respect of equipment and machinery, insufficient training and instructing, lack of special-purposed facilities, etc may be named the $1^{\text {st }}$, the $2^{\text {nd }}, \ldots$, the $m$ trauma prevention means. Such individual trauma causes as violation of technological process, negligent disregard of safety means, drunkenness, etc may be named the $1^{\text {st }}, 2^{\text {nd }}, \ldots$, the $n$ labour discipline violations. Here is the modelling of the matrix game:

$$
\left\|a_{i j}\right\|_{m \cdot n}
$$

where $m$ lines correspond to preventive means and $n$ columns correspond to labour discipline violations.

Let $d_{i j}$ be part of the number of traumas caused by violation $j$ that can be prevented by means of total elimination of cause $i$ on the part of employers (upon complete realisation of prevention $i$ ), and let $b_{i}$ be the number of traumas caused by cause $i$ dependent on employers that can be used for reducing the total number of traumas upon complete realisation of prevention $i$. Then

$$
a_{i j}=b_{i}+d_{i j} \text {. }
$$

Naturally, these figures/numbers are random quantities forecast on the basis of many years' statistical data or just the arithmetical mean of the number of traumas occurred due to cause $i$.

In order to assess the trauma prevention efficiency, it would be expedient to make a presumption that upon reducing part of the cause of traumas the number of traumas corresponding to this cause shall be decreased proportionally.

In the matrix game $\| a_{i j} \mid$ pure strategies of the employers shall be as follows:

1) To choose the $1^{\text {st }}$ line (ie to realise the $1^{\text {st }}$ prevention means);

2) To choose the $2^{\text {nd }}$ line (ie to realise the $2^{\text {nd }}$ prevention means);

........

m) To choose line $m$ (ie to realise prevention means $m$ ). If

$$
\max _{i} \min _{j} a_{i j}=a_{k l}=V_{1}
$$

by choosing prevention $k$, the employer shall prevent on average $V_{1}$ traumas irrespective of violations committed by employees.

Optimal mixed strategies $\left(x_{1}, x_{2}, \ldots, x_{\mathrm{m}}\right)$ are obtained upon solving the problem of linear programming [2]:

$\max V$

$$
\begin{aligned}
& \sum_{i=1}^{m} a_{i j} x_{i} \geq V, \quad j=1, \ldots, n, \\
& \sum_{i=1}^{m} x_{i}=1, \quad x_{i} \geq 0, \quad i=1, \ldots, m .
\end{aligned}
$$


Numbers $x_{i}$ show the efficiency (significance) of prevention means $i$.

If prevention means can be realised on a partial basis, numbers $x_{i}$ show what part of prevention $i$ we have to realise in order to prevent on average $V_{0}$ traumas irrespective of the behaviour of employees. Number $V_{0}$ satisfies inequality $V_{0}>V_{1}$. (Game value $V_{0}$, obtained by using mixed optimal strategies shall always be not less/ lower than the guaranteed gain obtained by choosing pure strategy).

Upon choosing the optimal behaviour herein the prevention means realisation price has not been taken into account. Very often the most efficient means can turn out to be too expensive. Therefore, before choosing means for realisation we have to know realisation prices of each of them.

Let $c_{i}$ be an amount of monetary funds required for complete elimination of trauma cause $i$ (for complete realisation of prevention $i$ ). Then $a_{i j} / c_{i}$ shall be reduction of the number of traumas upon investing one monetary unit into prevention means $i$ (having violation $j$ ). Here is the following matrix game:

$$
\left\|a_{i j} / c_{i}\right\| \text {. }
$$

In case when funds available $c \leq c_{i}, \quad i=1, \ldots, m$, pure strategies of the employers shall be:

1) To invest all the funds allocated for trauma prevention into the $1^{\text {st }}$ means;

2) To invest all the funds allocated for trauma prevention into the $2^{\text {nd }}$ means;

m) To invest all the funds allocated for trauma prevention into means $m$.

If

$$
\max _{i} \min _{j} a_{i j} / c_{i}=a_{k l} / c_{k}=W_{1}
$$

by choosing prevention $k$, the employer shall prevent on average $W_{1} \cdot c$ traumas irrespective of violations committed by employees.

Mixed strategy is a redistribution of funds $c$ in portions, ie allocation of sum $z_{i}$ for prevention means $i$. Here $z_{1}+z_{2}+\ldots+z_{\mathrm{m}}=c$ and $z_{i} \geq 0$ for all $i=1, \ldots \mathrm{m}$. The alternative between optimal pure or mixed strategies depends on the availability of any information about "nature" states, ie about discipline, prudence, qualification, etc of employees. In other words, we can know nothing about what percentage (or what portion) of employees commit each of the violations $\left(1^{\text {st }}, 2^{\text {nd }}, \ldots\right.$, violation $\left.n\right)$ or we can forecast these numbers on the basis of statistical data.

When we have no information about possible violations, we can find the optimal investment of the sum $c$ on solving the problem of linear programming:

$$
\begin{aligned}
& \max W \\
& \sum_{i=1}^{m} a_{i j} x_{i} \geq W, \quad j=1, \ldots, n ;
\end{aligned}
$$

$$
\begin{aligned}
& \sum_{i=1}^{m} c_{i} x_{i}=c ; \\
& 0 \leq x_{i} \leq 1, \quad i=1, \ldots, m .
\end{aligned}
$$

Let the value of this game be number $W_{0}$. Then will be an average number of prevented traumas guaranteed in the sense that it is absolutely independent of the necessity to know what violations have been committed by employees. This trauma reduction number will be achieved on investing $z_{1}=c \cdot x_{1}$ of monetary funds into the $1^{\text {st }}$ trauma prevention means, $z_{2}=c \cdot x_{2}$ of monetary funds into the $2^{\text {nd }}$ trauma prevention means, .., and $z_{m}=c \cdot x_{m}$ of monetary means into trauma prevention means $\mathrm{m}$.

Certain amount of traumas occur not owing to one (employer's or employee's) fault but because of both causes: insufficient trauma prevention and violations of individual labour safety regulations. Information on the variation of the number of traumas according to accident causes should be very informative in this regard by indicating the percentage share of employer's fault (cause) and the percentage share of employee's fault per trauma.

According to available data [1], each trauma cause is of $100 \%$, ie it is unique per certain number of traumas.

By going deeper into the differentiation of causes we would have more accurate statistical data and could be more precise in forecasting numbers $b_{i}$ and $d_{i j}$.

\section{Solution of pattern/example/sample/specimen}

The pattern we are solving is based upon rather relative numbers because the available statistical data is not plentiful. Therefore, it will be just an illustration of the proposed methodology.

We shall simulate the following matrix game by using the statistical data of "Causes and Number of Fatal and Grave Accidents in Building Sites in 1991-1995" [1].

$$
\left\|a_{i j}\right\|=\left\|b_{i}+d_{i j}\right\|=\left(\begin{array}{ccccc}
1+1 & 1+0 & 1+0 & 1+0 & 1 \\
0,4+0,6 & 0,4+0 & 0,4+0 & 0,4+0 & 0,4 \\
4,4+1 & 4,4+0,8 & 4,4+1 & 4,4+2 & 4,4 \\
1,6+0 & 1,6+0 & 1,6+0,8 & 1,6+1 & 1,6 \\
1,6+1 & 1,6+0 & 1,6+0 & 1,6+0 & 1,6
\end{array}\right)
$$

Numbers $b_{i}$ of the fifth column have been obtained after finding the average number of fatal traumas per year, that is dependent on the following causes:

1) Constructional defects of machines and mechanisms, exploitation/operation of improper machines and mechanisms $\left(b_{1}=1\right)$.

2) Imperfection of the technological process $\left(b_{2}=0,4\right)$.

3) Unsatisfactory organisation and supervision of work procedures $\left(b_{3}=4,4\right)$. 
4) Unsatisfactory condition of workplaces, structures and territories, lack of labour safety means $\left(b_{4}=1,6\right)$.

5) Insufficient training on safety labour means $\left(b_{5}=1,6\right)$.

Let us call the elimination of the above-mentioned causes the $1^{\mathrm{st}}, 2^{\text {nd }}, \ldots, 5^{\text {th }}$ prevention means. Selection of a prevention means shall include selection of the line in the matrix game $\left\|a_{i j}\right\|$.

In our pattern/example the first four columns of matrix $\left\|a_{i j}\right\|$ correspond to mistakes and violations of employees (let us mark off $d_{j}$ to be the average number of fatal traumas related to the above mistakes and violations per year):

1) Violation of technological process, violations of exploitation/operation of machines and machinery $\left(d_{1}=3,6\right)$.

2) Violations of exploitation/operation of means of transport, violations of road traffic regulations $\left(d_{2}=2,8\right)$.

3) Failure to use individual protection means $\left(d_{3}=1,8\right)$.

4) Violations of labour and industrial discipline $\left(d_{4}=5\right)$

It would be expedient that numbers $d_{i j}$ should be provided with more detailed statistical data, but in the absence of which we can base ourselves on the experts' findings.

$$
\text { In all cases } \sum_{i=1}^{5} d_{i j} \leq d_{j} \text {. }
$$

The monetary amount $C$ shall be necessary for the realisation of all prevention means, ie elimination of all trauma causes (during a certain period of time) dependent on the employers. Let $10 \%$ of it comprise expenses intended for complete realisation of the $1^{\text {st }}$ prevention $\left(C_{1}=0,1 c\right), 5 \%$ for the $2^{\text {nd }}$ prevention $\left(C_{2}=0,05 c\right)$, $50 \%$ for the $3^{\text {rd }}$ prevention $\left(C_{3}=0,5 c\right), 20 \%$ for the $4^{\text {th }}$ prevention $\left(C_{4}=0,2 c\right)$ and $15 \%$ for the $5^{\text {th }}$ prevention $\left(C_{5}=0,15 c\right)$ (percentage presentation has a relative value).

In order to find the optimal allocation of funds intended for trauma prevention we do not need to know the total sum/amount $C$. Quite enough will be to know the above-mentioned percentage, ie what portion of the total amount is required for the realisation of each prevention means.

Let us assume that we have $50 \%$ of the required amount $C$. After solving the problem of linear programming (1) by using the simulated matrix $a_{i j}$, we get the optimal plan $\left(x_{1} ; x_{2} ; x_{3} ; x_{4} ; x_{5}\right)=(1 ; 0 ; 0,5 ; 0 ; 1)$ and the optimal value of goal function $W_{0}=4,8$. This means that on the basis of optimal behaviour we have to carry out complete realisation of the $1^{\text {st }}$ and $5^{\text {th }}$ prevention means, whereas the remaining funds shall be allotted for realisation of the $3^{\text {rd }}$ prevention means, thus only partially $(50 \%)$ eliminating the third cause of traumatism.
Then, if employees do not commit the above-mentioned violations, we could annually reduce the number of fatal traumas on average by 4,8 units. In case the nature and frequency of employees' violations and missteps remains the same as during previous years, we may expect that the number of fatal traumas would annually decrease on average by 9,2 units. All these statements are based upon the presumption that without implementing any prevention means the average number of traumas will not decrease and will remain on the level of previous years. The described results have been obtained when the optimal criterion (the first one) in allocating funds for trauma prevention was the reduction of number of fatal accidents.

There is another (second one) possible optimal criterion - reduction of the total number of fatal and grave accidents. That is why analogue calculations have been carried out by using statistical data on the total number of fatal and grave accidents on building sites from 1991 to 1995. The discovered optimal allocation of funds intended for trauma prevention when aiming for reduction of total number of accidents (fatal or grave) differs from the optimal allocation of funds aimed at reducing only the number of fatal accidents. A more detailed presentation of differences is provided in Tables 1 and 2 .

Table 1. Optimal allocation of funds intended for preventing fatal accidents on a building site

\begin{tabular}{|c|c|c|c|c|c|}
\hline $\begin{array}{c}\text { The available } \\
\text { percentage of the } \\
\text { total required } \\
\text { amount C }\end{array}$ & \multicolumn{6}{|c|}{$\begin{array}{c}\text { Percentage portion of the required amount } \\
c_{i} \text { allocated for each prevention means }\end{array}$} \\
\cline { 2 - 7 } & 1 & 2 & 3 & 4 & 5 \\
\hline 10 & 0 & 0 & 0 & 0 & 66.67 \\
\hline 20 & 50 & 0 & 0 & 0 & 100 \\
\hline 30 & 100 & 0 & 10 & 0 & 100 \\
\hline 40 & 100 & 0 & 30 & 0 & 100 \\
\hline 50 & 100 & 0 & 50 & 0 & 100 \\
\hline 60 & 100 & 0 & 70 & 0 & 100 \\
\hline 70 & 100 & 0 & 90 & 0 & 100 \\
\hline 80 & 100 & 0 & 100 & 25 & 100 \\
\hline 90 & 100 & 0 & 100 & 75 & 100 \\
\hline 100 & 100 & 100 & 100 & 100 & 100 \\
\hline
\end{tabular}

Efficiency of prevention means can be evaluated by comparing optimal mixed strategies of matrix games obtained by changing amount of the available funds.

This percentage shows that according to the first criterion, first of all funds should be allocated to the $5^{\text {th }}$ prevention means and then respectively to the $1^{\text {st }}, 3^{\text {rd }}$ and $4^{\text {th }}$. As for the $2^{\text {nd }}$ prevention means, it is the least efficient and therefore the funds shall be allocated only in case other prevention means have been supplied with funds in full. 
Table 2. Optimal allocation of funds intended for preventing fatal and grave accidents on a building site

\begin{tabular}{|c|c|c|c|c|c|}
\hline $\begin{array}{c}\text { The available } \\
\text { percentage of the } \\
\text { total required } \\
\text { amount } C\end{array}$ & \multicolumn{4}{|c|}{$\begin{array}{c}\text { Percentage portion of the required amount } \\
c_{i} \text { allocated for each prevention means }\end{array}$} \\
\cline { 2 - 7 } & 1 & 2 & 3 & 4 & 5 \\
\hline 10 & 100 & 0 & 0 & 0 & \\
\hline 20 & 100 & 0 & 0 & 50 & 0 \\
\hline 30 & 100 & 0 & 0 & 100 & 0 \\
\hline 40 & 100 & 0 & 20 & 100 & 0 \\
\hline 50 & 100 & 0 & 40 & 100 & 0 \\
\hline 60 & 100 & 0 & 60 & 100 & 0 \\
\hline 70 & 100 & 0 & $\frac{80}{10}$ & 100 & 0 \\
\hline 80 & 100 & 0 & 100 & 100 & 0 \\
\hline 90 & 100 & 0 & 100 & 100 & 66.67 \\
\hline 100 & 100 & 100 & 100 & 100 & 100 \\
\hline
\end{tabular}

Table 3. Expected decrease of average number of accidents depending on the amount of the funds invested for trauma prevention

\begin{tabular}{|c|c|c|}
\hline $\begin{array}{c}\text { The invested } \\
\text { percentage } \\
\text { portion of the } \\
\text { total required } \\
\text { amount } C\end{array}$ & $\begin{array}{c}\text { The expected average number of prevented fatal } \\
\text { and grave accidents achieved due to trauma } \\
\text { prevention }\end{array}$ \\
\hline 10 & $\begin{array}{c}\text { Whot commit } \\
\text { violations or } \\
\text { mistakes }\end{array}$ & $\begin{array}{c}\text { Nature and frequency of } \\
\text { employees' violations and } \\
\text { missteps remains the same } \\
\text { as in previous years }\end{array}$ \\
\hline 20 & 4,4 & 7,4 \\
\hline 30 & 7,6 & 12,9 \\
\hline 40 & 10,8 & 18,4 \\
\hline 50 & 13,16 & 24,4 \\
\hline 60 & 17,88 & 30,4 \\
\hline 70 & 20,24 & 36,4 \\
\hline 80 & 22,6 & 42,36 \\
\hline 90 & 24,7334 & 48,4 \\
\hline 100 & 26,8 & 57,73334 \\
\hline
\end{tabular}

For the prevention of grave and fatal accidents (according to the second criterion), the most efficient is the $1^{\text {st }}$ prevention means, the second one in terms of efficiency is the $4^{\text {th }}$ prevention means followed by $3^{\text {rd }}, 5^{\text {th }}$ and the least efficient $2^{\text {nd }}$. The choice should be made between the two criteria (goals), ie to reduce either the number of fatal accidents or the total number of total and grave accidents. However, it should be remembered that when achieving the latter goal, the average number of prevented fatal cases will be smaller than the number of cases of the first criterion.
The optimal funds allocation strategies for trauma prevention, investigation of efficiency of prevention means and the average/means gains (Table 3) have been obtained by using procedure LP of software SAS/OR [8].

\section{Findings}

1. On the basis of statistical data regarding accidents and causes thereof, the matrix game can be used as a mathematical model for optimal allocation of funds intended for trauma prevention and for the efficiency assessment of prevention means.

2. A certain amount of traumas occurs not owing to one (employer's or employee's) fault but because of both causes: insufficient trauma prevention and violations of individual labour safety regulations. In this case we should know what percentage share of fault belongs to the employer and what percentage share of fault belongs to the employee. According to available data [1], each trauma cause mentioned in Tables is of $100 \%$, ie it is unique per certain number of traumas.

3. By going deeper into the differentiation of causes we would have more accurate statistical data and could be more precise in forecasting numbers $b_{i}$ and $d_{i j}$. Then the efficiency analysis of prevention means suggested in this research would be more reliable and the recommended optimal allocation of funds intended for reducing the number of traumas would be better motivated.

\section{References}

1. Cyras P., Jaras A. Safety of people on building sites. Civil Engineering (Statyba), Vol 8, No 4. Vilnius: Technika, 1996, p 110-116 (in Lithuanian).

2. Dubin G. N., Suzdal V. G. Introduction to the applied theory of games (Введение в прикладную теорию игр). Moscow: Nauka, 1981. 336 p (in Russian).

3. Peldshus F., Zavadskas E. K. Matrix games in building technology and management (Matriciniai lošimai statybos technologijoje ir vadyboje). Vilnius: Technika, $1997.134 \mathrm{p}$ (in Lithuanian).

4. Topol N. G., Dombrovsky M. Imitations games within the systems of fire safety support. Research papers (Имитационные игры в системах обеспечения пожарной безопасности. Сб. науч. тр.). Moscow: VIPTI MVD RF, 1993. p 122-126.

5. Weber S. A Modified Analytic Hierarchy Process for Automated Manufacturing Decisions. Interfaces, Vol 23, No 4, 1993, p 75-84.

6. Taha, Hemdy, A. Introduction to the investigation of operations. $6^{\text {th }}$ edition: Translation from English (Введение в исследование операций. 6-е издание. Пер. с англ.). М.: Publishing House "Williams", 2001. 912 p (in Russian).

7. Millet I. A Novena to Saint Anthony, o How to Find Inventory by not Looking. Interfaces, Vol 24, No 2, 1994 , p 69-75.

8. SAS/OR User's Guide, Version 6, First edition. Cary, NC: SAS Institute Inc., 1993. $570 \mathrm{p}$ 